\title{
A model to analyse students' cooperative idea generation in conceptual design
}

\author{
Magnus Hultén ${ }^{1}$ (D) Henrik Artman² David House $^{2}$
}

Accepted: 18 October 2016/Published online: 27 October 2016

(C) The Author(s) 2016. This article is published with open access at Springerlink.com

\begin{abstract}
In this article we focus on the co-creation of ideas. Through the use of concepts from collaborative learning and communication theory we suggest a model that will enable the cooperative nature of creative design tasks to emerge. Four objectives of the model are stated and elaborated on in the paper: that the model should be anchored in previous research; that it should allow for collaborative aspects of creative design to be accounted for; that it should address the mechanisms by which new ideas are generated, embraced and cultivated during actual design; and that it should have a firm theoretical grounding. The model is also exemplified by two test sessions where two student pairs perform a timeconstrained design task. We hope that the model can play a role both as an educational tool to be used by students and a teacher in design education, but primarily as a model to analyse students' cooperative idea generation in conceptual design.
\end{abstract}

Keywords Creativity $\cdot$ Collaborative design $\cdot$ Model $\cdot$ Conceptual design

\section{Introduction}

Over the last few decades, education at all levels has seen a strong emphasis on widening and rearranged curricula in order to make room for innovation, creativity and design (e.g. Badran 2007; Cheung 2012; Cropley and Cropley 2010; Esjeholm 2015; Howard et al.

Magnus Hultén

magnus.hulten@liu.se

Henrik Artman

artman@kth.se

David House

davidh@speech.kht.se

1 Department of Social and Welfare Studies, Linköping University, 60174 Norrköping, Sweden

2 KTH Royal Institute of Technology, 10044 Stockholm, Sweden 
2008; Rutland and Barlex 2008; Zhou 2012). Much research effort has been put into defining and characterising creativity and creative design processes (examples of more extensive overviews: Howard et al. 2008; Plucker et al. 2004). For example, creative designs can be evaluated through concepts such as "relevance and effectiveness", "novelty", "elegance" and "generalisability" (Cropley and Cropley 2010; Zhou 2012, p. 349). Similarly, qualities of creative processes have been proposed in terms of "divergent thinking", "investigative work" and "risk taking", and through recurrent phases of "analysis", "synthesis" and "evaluation" (Lindström 2006; Wong and Siu 2012). Alongside conceptual developments, research has also developed descriptive and educational models on creative design, based on the synthesis of research on creativity and creative design, theories of learning, and new empirical findings (e.g. Dorst and Cross 2001; Howard et al. 2008; Rivard and Faste 2012; Wong and Siu 2012). Furthermore, the use of exemplars to clarify the goals of creative design in educational settings has been proposed (Hendry and Tomitsch 2014); the importance of meeting the emotional needs of students in order to foster creative design (Siu and Wong 2016); and how prior conceptual knowledge and the balance between domain and process knowledge can affect student creativity in design (Christiaans and Venselaar 2005; Esjeholm 2015). These are just some examples of research on creative design; there is certainly no lack of concepts, models or teaching tools and techniques in this area which point to the importance of contributions to the field, building on previous insights.

The aim of this study is to develop a model that will enable analysis of cooperative idea generation in conceptual design. The first objective of the model is to anchor it in previous and relevant research, more specifically in a model of conceptual design developed by Dorst and Cross (2001). The second objective is that the model should allow for collaborative aspects of creative design to be accounted for. Not much attention has been given to the collaborative aspects of creative processes (e.g. Artman et al. 2014; Juhl and Lindegaard 2013; Ramberg et al. 2013). In particular, decision-making processes have been highlighted as an area of importance for further study (e.g. Stempfle and Badke-Schaub 2002; Wiltschnig et al. 2013; Toh and Miller 2015, p. 115). We believe that both design education as well as research on creative design more generally will benefit from studies that-like the current study - try to understand and conceptualize how novices develop and perform creative design collaboratively. The third objective of the model is that it should address the mechanisms by which new ideas are generated, embraced and cultivated during actual design, something that previous research has pointed out is lacking in existing models (Howard et al. 2008, p. 176; Dorst and Cross 2001, p. 425; Plucker et al. 2004; Toh and Miller 2015). The fourth and final objective is to give the model developed a firm theoretical grounding. As a way to illustrate and exemplify the use of the model, two test sessions were implemented with two pairs of students.

The model presented in this article was developed by the authors of this study out of a need to understand the creative processes that took place during interactionaries (a short design task lasting from about 10-30 min that a team of students had to solve overtly in front of the researchers. See Artman et al. 2014; Ramberg et al. 2013). Development of the model was initiated by applying the concept of transformation (cf. Selander 2008), as this concept could elucidate the dynamics of the ideation process. Along the way, new concepts such as common ground were added. We gradually started to connect and link the concepts to each other and made preliminary models aimed at capturing cooperative idea generation in conceptual design. Finally, we arrived at the model that will be presented here. As a pure theoretical presentation of the model would have risked being too abstract, test sessions 
were included in order to illustrate possible uses/applications of the model in analysing collaborative conceptual design.

\section{A model of cooperative creative design}

\section{Creative processes}

The first objective was to anchor our model in a model of conceptual design developed by Dorst and Cross (2001).

Cross (1997) argues that what we call a "creative event" is not the generation of a solution to a problem, but rather the building of a "bridge" between what is called "the problem space" and "the solution space", and this happens through the identification of a key concept. Dorst and Cross (2001) confirm this in their research, and also suggest that the relation between problem and solution spaces is evolving and unstable until fixed (at least temporarily) by a similar "bridge". They call the "creative event" the moment at which this bridge is formed. Dorst and Cross also suggest that "the 'creative' aspect of design can be described by introducing the notions of 'default' and 'surprise' problem/solution spaces" (2001, p. 436).

The model (see Fig. 1) proposed by Dorst and Cross (2001) builds on work by Maher et al. (1996). The model primarily covers the conceptual design phase, which is the phase that is the focus of this paper, and thus not the whole design process including the identification and specification of the problem/need, the conceptual design (possible technical solutions), the embodiment phase (the more concrete design of the technical solution) etc. (Howard et al. 2008).

The primary aspect of the model in Fig. 1 is a distinction between two spaces: the problem space and the solution space, and the gradual evolution of and interaction between these spaces. Thus we cannot talk of a "design problem" as this, as well as the solution, take on different forms during the process. In this paper we will not go into the evolution of how the problem space and solutions space are framed since this has been discussed elsewhere (Dorst 2006, 2011; Dorst and Cross 2001). Thus, we have to keep in mind that

\section{Problem-Space Dimension \\ Solution-Space Dimension \\ $\mathbf{P}(\mathbf{t}) \quad$ initial problem space \\ $P(t+1)$ partial structuring of problem space \\ $S(t) \quad$ initial solution space \\ $\mathbf{S}(\mathbf{t + 1 )}$ partial structuring of solution space \\ $\mathbf{S}(\mathbf{t + 2})$ developed structuring of solution space \\ $\mathbf{P}(\mathbf{t}+\mathbf{2})$ developed structuring of problem space}

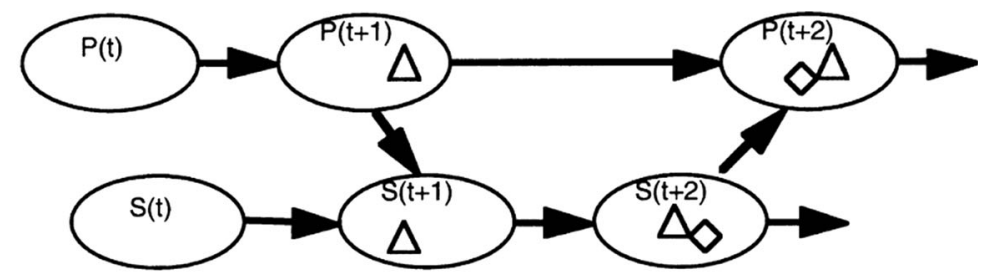

Fig. 1 A model of creativity by Dorst and Cross (2001, p. 435). Reproduced by permission of the authors 
when talking of a "design problem" this is not a fixed problem but something that continuously evolves during the process of design through framing and reframing relevant aspects of what designers consider important to the problem space. The co-evolution model, which was originally validated in a think-aloud task performed alone by professional designers, has received empirical validation in cooperative settings in a study by Wiltschnig et al. (2013). In their studies of a product development teams' meetings they found that a co-evolution thesis well matched the evolution of ideas in the conceptgeneration phase. However, the model lacks a firm theoretical grounding, and it does not explicitly address cooperative aspects of conceptual design, or the mechanism by which ideas are generated. Before returning to the model by Dorst and Cross (2001) and anchoring it to the model proposed in this study, we will address the other three objectives of our model.

\section{Common ground}

In order to address the second objective, that the model should allow for collaborative aspects of creative design to be accounted for, we decided to turn to the concept of common ground (a theoretical concept that also addresses the fourth objective, the theoretical basis of the model).

Studying and understanding collaborative creativity needs a different focus than when studying the same type of phenomenon in a non-collaborative setting. Designer teams not only have to be creative; they also need to reach a specific high-end goal in collaboration (Atman et al. 1999, 2005; Bijker 1995; Klein and Kleinman 2002). Among other things, this means that a design team needs to maintain some sort of mutual understanding regarding beliefs, assumptions and knowledge that they find relevant in order to develop a joint design brief (c.f. Stempfle and Badke-Schaub 2002, p. 492; Toh and Miller 2015; Wiltschnig et al. 2013). We propose that they need to maintain a "common ground" (e.g. Brennan 1998; Clark and Brennan 1991; Clark and Marshall 1981).

Common ground is a concept that was developed within linguistics and psychology in the 1970s and 1980s, and one that has continued to attract considerable attention (e.g. Brennan 1998; Clark and Brennan 1991; Clark and Marshall 1981) as well as being challenged (e.g. Pickering and Garrod 2004). It aims to explain how people use and cocreate mutual beliefs and knowledge in order for a dialogue to evolve, thus addressing objective 2, collaborative aspects of creative design. Similar aspects have been considered in previous research (e.g. Wiltschnig et al. 2013); however, to our knowledge, not from a theoretical point of view.

A dialogue in which two or more participants contribute needs to have some basic common ground in terms of how the participants show acceptance of the conversation (Clark and Brennan 1991). The speaker often anticipates the addressee's understanding either by the use of certain words that are believed to be common or by awaiting the addressee's response. Nodding and/or verbal feedback in terms of "yeah" and "OK" are examples of showing that an addressee understands the speaker. When the addressee is unsure about the meaning of what the speaker says, she or he might ask for a clarification of the utterance, or even declare something about the situation, and thereby indicate that the dialogue participants have to revert to a more basic common ground. Pickering and Garrod (2004) also introduce the concept of implicit common ground in order to acknowledge the more automatic alignment that occurs in most conversations. This contrasts to a common ground that needs more thorough processing by both participants in order to be reached. In this way, conversations proceed through stages where the 
participants easily understand each other and other stages where more work and effort is put into the conversation in order for clarification and a common understanding/acceptance to be accomplished. In this study we argue that the creative parts of the collaboration are of the latter kind; they demand more cognitive effort from the participants.

Thus, grounding and finding common ground is a dynamic process starting at one point and developing throughout the design task. This happens not only through talk, but also by using sketches, gestures, enactments or drama (Arvola and Artman 2007; Juhl and Lindegaard 2013; Ramberg et al. 2013; Sun et al. 2014; Suwa and Tversky 1997; Tholander et al. 2008). For example Juhl and Lindegaard (2013), in their studies of engineering students solving design tasks, conclude that sketching helped the students synthesize ideas, and facilitated mutual understanding and decision-making. In summary, some of the methods of creating common ground can be quite strong, both because the interlocutors must have a shared understanding of the situation and what is expressed, and also because they create a strong context in that the different forms of expressions include or presuppose the circumstance.

\section{Transformation}

If grounding can be seen as a necessary process in any collaborative creative process, of equal importance is the expansion of common ground. While psychologists and linguists have mainly been interested in strategies for maintaining common ground, the context of creativity has attracted interest in challenges of mutual understanding. In order to address the third objective, to allow the mechanisms by which new ideas are generated, embraced and cultivated during actual design to be accounted for, we turned to the concept of transformation (the concept of transformation also addresses the fourth objective, the theoretical basis of the model).

Creative processes are often characterised by the ability to diverge from conventional ideas, for example, being able to perform "divergent thinking", "investigative work", "risk taking" or reach "surprise" solutions (e.g. Bijker 1995; Dorst and Cross 2001; Klein and Kleinman 2002; Sundholm et al. 2004; Wong and Siu 2012). We shall use the term 'transformation' to signify similar processes that expand common ground. The reason to choose transformation instead of other existing concepts depicting creative events is because we want our model to be of relevance primarily for educational purposes. We thus emphasise the need to develop different models for educational purposes than for purposes of characterising creative design. This distinction is not always made clear in the modelling literature, and is often treated more as a question of gradually becoming an expert designer, and thus as a way of modelling novice and expert behaviours (e.g. Atman et al. 1999, 2007). While models for purposes of characterising creative design generally focus on a more overarching level of creative design processes, for example on "pivotal" contributions, those that are "truly" creative, or that imply "risk taking", we want analytical concepts that allow for each contribution to the creative process to be depicted and analysed, no matter how minor or major it might seem to be. We believe the concept of transformation to be suited for this purpose.

Transformation as a pivotal characteristic of learning processes has been suggested in several theories, i.e. developmental psychology (Vygotsky 1986), activity theory (Engeström 1987), distributed cognitions (Salomon 1993; Hutchins 1995), and recently in designs for learning (Selander 2008). These different theories all have slightly different contexts for discussing and defining transformation; however, in essence, they all involve changes of meaning in the communicative process as well as changes that occur in the various 
medias (movies, books, imagery,...) and modes (spoken language, sound,...) of communication (Jewitt 2008, p. 246).

Selander and colleagues have suggested a theoretical framework called learning design sequences (LDS) (Selander 2008; Selander and Kress 2010). Here, learning is defined as "an increased capacity to use signs and engage meaningfully in different situations" (Selander 2008, p. 12). LDS is based on an institutionalised perspective and focuses on how actors connect and orchestrate many multimodal transformations in order to form a "representation", i.e. the "learning outcome". This in turn can be subjected to new transformations in order to be developed further. The use of different media to express and represent modes is an important part of the LDS framework, which includes all forms of semiotic and bodily expressions. This makes it particularly appropriate for creative work since much creative work includes enactments, gestures, and dramatization [see Arvola and Artman (2007) and Tholander et al. (2008) for other examples of creative design work]. Transformations related to these aspects of creative collaboration expand on common ground. In the next section we will present our model of collaborative creative design.

\section{The model}

In accordance with Dorst and Cross (2001) we regard the design brief as a basic starting point in the problem space. From this the participants must create a common ground from which the process starts. Any kind of attempt to initiate a challenge to common ground in terms of creative ideas might be directly refuted, which would lead to a closed transformation and a new attempt (see Fig. 2). Other attempts to challenge the common ground might also turn into an open transformation-a transformation which is tentatively accepted but may quickly turn into a closed transformation. However, an open transformation might also turn into a transformative closure which then leads to a strong commitment by the participants in that they find it a viable concept to investigate further. This resembles the formation of a "bridge" in the model of Dorst and Cross (2001). The line of thought might then be abandoned and the participants recur to the design brief and the instructions - the task-constraints-in order to re-establish the relevant common ground for the task. In this circular process, both the problem space and the solution space evolve

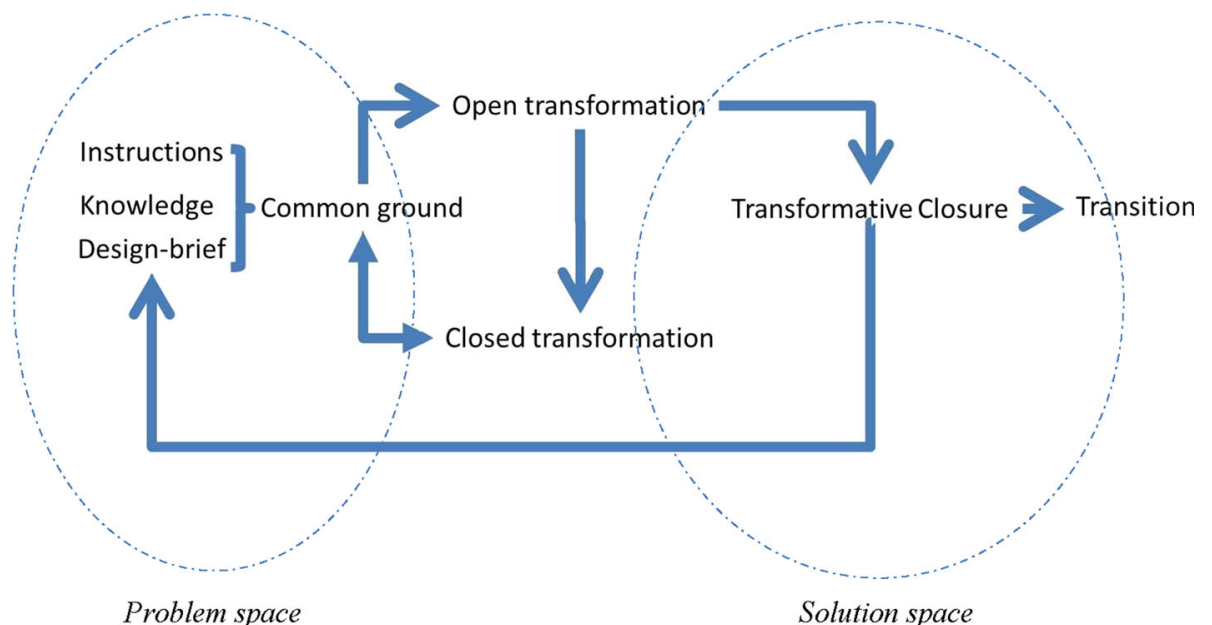

Fig. 2 A model describing collaborative creative design processes 
(Fig. 1; Dorst 2006; Dorst and Cross 2001). The model presented in this study does not go into conceptualizing how these spaces evolve, but instead focuses on the micro-processes involved in this co-evolution. As such, we see the model as providing a complementarymicro-perspective to the model presented by Dorst and Cross (2001, Fig. 1), and believe it focuses on the mechanisms of the co-creation of ideas (c.f. Toh and Miller 2015; Wiltschnig et al. 2013).

At the transformative closure the concept is given a more tangible and persistent representation, typically in terms of a sketch or a model. We call this a transition as it is a collection of different representations that are now compromised into one or more representations, which may turn into the main focus of the dialogue. The transition is more a shift in perspective than a transformation that challenges the common ground. The shift in perspective can develop into a tangible focus on form, placement, aesthetics, etc. We will elaborate on and problematize this through our examples later on.

Below are inductively-stipulated definitions or descriptions:

Common ground Common ground is the state in which the collaboration proceeds as an increased mutual understanding of the task, what to do, and what not to do.

Open Open transformations are close to what we generally think of as transformation creative leaps. This is when the implicit common ground is challenged in such a way that it changes some generic world view or semantic understanding of a concept.

Closed Closed transformations can be defined as abandoned ideas or dead transformation ends. They occur when one or both participants regard a specific idea or generated direction of the project as not sufficient to continue with. The consequence of a closed transformation is that the idea or the direction is abandoned and the participants have to recur to previous common ground.

Transformative Transformative closure is a mutual social agreement. In general, it is closure when two or more participants find themselves in agreement on what is a viable idea. The closure does not lend itself to leaps in creativity, but establishes a new common ground for the remaining creative work.

Transitions Transitions are not transformations per se, but rather shifts in perspective either as a consequence of the idea being put into a sketch or put into a new context where the agreed upon ideas are developed. It is usually the part of the conceptual phase where the idea takes on a more concrete physical form, but before going into the embodiment phase. The material used in a transition influences and may even stipulate the development of the proposal (Buxton 2007; Sun et al. 2014; Suwa and Tversky 1997).

\section{Design of the test sessions}

For the test sessions we used an educational format called the interactionary (see Ramberg et al. 2013), consisting of a short design task (lasting from about 10 to $30 \mathrm{~min}$ ) that a team of students had to solve overtly and in front of the teacher and fellow students. Such a task 
is a way of developing student performative creative skills as well as a way to kick-start innovative processes (Artman et al. 2014; Ramberg et al. 2013). Even though this type of time-constrained design task does by no means cover all possible cases of collaborative conceptual design, it can provide an educationally relevant example and thus relevant qualitative data that can be used to explore and illustrate possible applications of the model. Even though the students in the test sessions were engineering students, we think the overall setting made it relevant also to similar tasks in primary and secondary technology and design education.

Two pairs of self-selected chemical engineering students were recruited from a group with basic knowledge in scent chemistry. The pairs were presented with the task of designing an interactive artefact based on "scent chatting". They had no previous experience in design, which means they were design novices. The reasons for the choices of student backgrounds (engineers with basic knowledge in scent chemistry) and design task (scent chatting) were that we wanted our test sessions to be examples of situations where the participants had some basic and relevant content knowledge related to the design task, and finally that they could be assumed to have a basic interest in developing new artefacts (thus the choice of recruiting students following engineering programs and not pure science programs) but that they were otherwise novices in design. The design task was somewhat "wicked" and open-ended to increase the opportunities for creative discussions and thus hopefully provide rich data for the analysis.

The student pairs worked together in a spacious room. The first pair (henceforth referred to as pair 1) consisted of two males, and the second pair (pair 2) consisted of a female and a male. At the start of each session, the participants received a document presenting a design brief on scent chatting (see Fig. 3) as well as interactive design aspects to consider (the concepts of temporality, dynamics, sequentiality, interactivity and context of use. On these, see Artman et al. 2014).

The participants were informed that they had $5 \mathrm{~min}$ to read, put questions to the teachers/researchers, and discuss within the pair. After that, they had $30 \mathrm{~min}$ to both distribute tasks and design their proposal. Besides presenting the task and objective of the study, we did not intervene during the design sessions. The participants were asked to create design proposals including an artefact (i.e. a physical representation of the design proposal in a chosen material) and a use-scenario with a special focus on interactive

\section{Design brief: Interactive scent (i-DOFT / scent chatting)}

The latest idea in digital communication is to use scent as a mediator of information and communication.

Your task is to design a concept for an interactive scent device for the company i-DOFT, based on the concept of scent chatting. The scents should not be static or too dominant, but should be dependent on circumstances, needs and objectives. The concept may not be based on unidirectional scent spread, and it should be linked to events in the environment Your design concept should therefore be able to create scents so that they can adapt to different situations where you may need scent.

Fig. 3 Design brief 
aspects of the artefact and its use. The participants were further informed that they were to give a presentation of their final proposal.

The design pairs were provided with various design resources (whiteboard, clay, paper, plastic paper, paper, scissors, Lego ${ }^{\mathrm{TM}}$, pencils, etc., see Fig. 4) to use in their design work. The room was spacious enough to allow the students to separate and work alone, as they deemed fit. The room was also equipped with a large whiteboard where they could sketch or present flow charts or other notations.

The design sessions were video-recorded from two different angles by the authors. That fact that the sessions were staged, that the authors of this paper were present during the sessions, and that the sessions were video-recorded, probably affected the discussions, for example the ideas that were proposed or accepted, the ideas that were refuted, etc., which is a limitation of this study. Selected examples of these sequences are presented and analysed in the analysis section. As the sessions were conducted in Swedish, the transcripts have been translated.

\section{Applying the model on data: analysing the test sessions}

In a previous study, analyses were performed of how frequently the participants addressed the various aspects of interaction during their design work [see Artman et al. (2014)]. In those analyses, three raters (the authors) independently observed the video and indexed in time when they felt that any of the five aspects of interaction were addressed by the students. After performing the individual, independent ratings the raters discussed and aligned their ratings (in terms of both when in time and what aspect the students addressed). The alignment discussion of the video also included a qualitative analysis of the content (e.g. reacting to smells, choosing a scent, etc.) and mode of expression (e.g. gesture, pointing, sketching, etc.). The final inter-rater reliability Rxy-coefficients were $65 \%$ (Group 1) and $79 \%$ (Group 2). The analyses [presented in Artman et al. (2014)] provide a systematic inventory of the ideas related to interaction design, without rating the quality of the contributions.

For the analysis in the present study, the video data was re-analysed using an interaction analysis approach (Jordan and Henderson 1995) to enable a better understanding of the participants' enactment of the different aspects of interaction design (the five aspects presented earlier) in relation to the theoretical concepts of our model. In applying the model to qualitative data, we have found it useful to find a starting point in "common ground". This can be a point where no ideas have yet been verbalized or a point where the

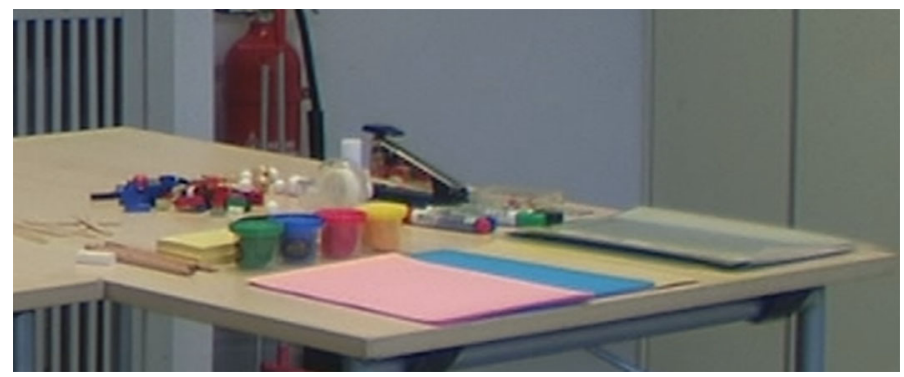

Fig. 4 The design studio with examples of design resources 
participants return to either the design brief or to a point where they explicitly state a need to restart the creative process. A first starting point in the test sessions was found just when or shortly after the pairs had read the design briefs, as they started their first discussions on possible solutions to the design task.

Another principal aspect of applying the model is that turns in the discussions which do not involve any type of ideas relevant to the task, such as when the participants talk about the weather, what they had for breakfast etc., should be treated as "blank", thus not covered by the analysis. Where in the model the discussion should start after a break is not given, but must be a question of interpreting the character of the discussion after such breaks.

Even though we performed the qualitative analysis on the whole body of material and thus on each turn in the discussions of the two test sessions (lasting approximately $30 \mathrm{~min}$ each), we will only present more detailed analysis of selected parts in order to illustrate principal aspects of the model. This means that most parts of the discussions will just be briefly or more generally characterised. Quantitative analysis has not been performed although we believe that quantitative data can be generated from the analysis.

Having the above more general considerations in mind we will give examples of applications of the model relating to the core concepts and aspects of the model below.

\section{Expanding and challenging common ground}

In both pair sessions, we found numerous instances where one of the participants introduced an idea or a proposal which functioned to expand or challenge the common ground. These proposals could either be accepted or rejected by the other participant. A proposal which is accepted creates what we term an open transformation i.e. a transformation that expands the common ground of the people involved in the communication. A proposal that is rejected creates what we term a closed transformation i.e. the idea is rejected due to lack of common ground.

Starting with pair 1, approximately 15 min into their discussion the idea they finally decide to go for is settled and a transformative closure is reached. But up to that point, several other viable ideas had been discussed, modified and/or refuted, and these are analysed in this section.

Pair 1 is starting their discussion broadly, discussing the problem and how to approach it, and in doing so they are expanding on the common ground in terms of their mutual understanding of the task/the problem space. Six minutes into their discussion Stripes (named after the pattern of his shirt) proposes two possible ideas to elaborate on-a product based on pheromones or something in relation to food. Chequered (also named after the pattern of his shirt) elaborates on the latter idea and introduces the idea of positive and negative scents. Stripes do not understand what Chequered means and he therefore poses a couple of clarifying questions. Now Chequered turns to the problem of sweating and proposes using scents to hide or eliminate unpleasant smells in the manner of a deodorant, and seems to propose that this function could be built into a sweatshirt.

Chequered: For example when you are sweaty. Some device that makes you smell good instead of bad. That adapts the smell ... Now I just take an idea, for example depending on how much sweat you exude or depending on your body temperature or something like that.... In order for you to smell good.

Stripes: So it regulates the smell from the body then.

Chequered: Yes, body odours, but it comes from a sweatshirt or something like that. 
Stripes: So something that is activated when the body is sweating so that it releases a scent, like a bodily activated deodorant ... Although a deodorant works differently, it kills the bacteria.

This initial proposal launched by Chequered is initially accepted by Stripes who mirrors the gesture and elaborates on the proposal (Fig. 5). Starting with the initial two-part proposal made by Stripes, what evolves is an open transformation in progress, where the participants continuously challenge and expand on common ground. Mirroring here is a gesture conveying the understanding of the concept, i.e. conveying common ground.

After this sequence they turn to a short discussion on how to divide the work. When returning to their discussion on which idea to go for, Chequered says "A deodorant you say" and after this they elaborate on a new type of deodorant, while the deodorantsweatshirt has been temporarily abandoned. They elaborate on the characteristics and functions of the deodorant for more than $2 \mathrm{~min}$, incorporating into this the idea of pheromones as one of its components. But then the idea of a sweater reappears:

Chequered: How would it be if we took that thing and made a sweater of it?

Stripes: Yes [laughs].

Chequered: A sweater that reacts to temperature.

Stripes: Definitely.

Chequered: Because often sweat sticks to sweaters and the sweaters start to smell

bad. And then you could have pheromones in that too, like a training sweater.

Stripes argues that there are already similar products on the market and mentions an example he knows of. At the same time, he elaborates on the idea by discussing how the pheromones could work and says that some mosquito protection could also be added to the concept. What we can follow here is a continuous challenge and expansion of common ground in an open transformation, gradually modifying the solution space. But it never settles; they do not reach agreement, a transformative closure; instead, this idea is refuted. Chequered, when returning to the brief, then notices they have to address questions on communication and information, which leads them to abandoning the ideas of both a deodorant and a sweatshirt, and a new proposal involving the use of a smartphone is introduced:

Chequered: And you want to link this to i-Doft which works with digital solutions [i-

Doft is the company in the brief that gave them the mission].

Stripes: [Also reading the brief] Digital communication, yes.

Chequered: And information. Perhaps, when you hold this telephone. When you hold the case of your telephone, then, depending on the temperature of your hand, scents
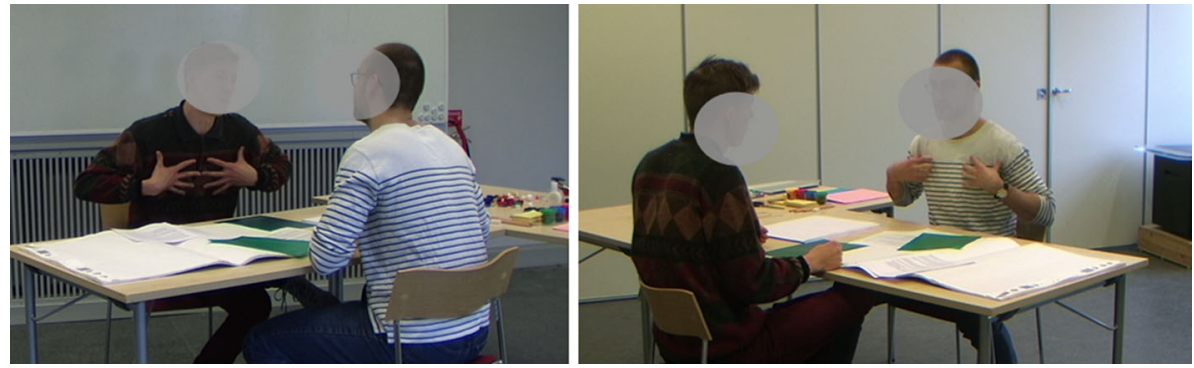

Fig. 5 Example of a sweating gesture and a mirroring gesture 
are released that perhaps makes you want to open a certain application or something similar.

Stripes: Yes, and when you send an SMS you also send a scent.

Chequered: Exactly. Something that is linked to the surface.

Stripes: When you are a grumpy you send a fart, that would be fun, right [laughs]. Or sending the scent of roses to one's beloved. When you send the rose-emoji.

Chequered: Exactly.

Stripes: Should we do that in our concept? In this we have the i-Doft concept.

Although several aspects that had previously been discussed reappear in a slightly modified context/idea as they are transformed to the digital solution, this provides an example of an open transformation becoming a closed transformation, with the participants returning to a previous common ground and a modified proposal. What eventually "closes" the open transformation is that they notice that the solution should be a digital solution, which, as they notice, the solutions they have discussed are not.

We will now take one example from the session of pair 2 which illustrates grounding taking place as a non-creative part of the discussions, and how such grounding can kill potentially creative leaps, the open transformation. In the sequence below, 12 min into their discussion, we find the participants focused on the brief, and trying to check that they have got everything.

Female: Gestures [reading the brief]. So if I make a heart sign [she makes a heart sign gesture], the system should be able to recognize that too.

Male: Yes, exactly, that is just as ... where was I?

Female: It was there [points to the brief with her pencil]

Male: Yes, and states of mind, that is possible to read, that's body language. That's relatively easy to read for a...

Female: For a computer.

Male: Yes. And instructions [continues to read the design specification from the brief], that is just when I write that I want to send this scent and then...

Female: Yes, it is just like programming, very basic.

Male: And gestures, it's just... yes.

Female: What type of gestures could one think of [She is making gestures, see Fig. 6]?

Male: Exactly, gestures that can be read by a camera.

Female: Does it have to be linked to a webcam? No, it doesn't. Say you have an infra-red camera that could recognize body heat and...
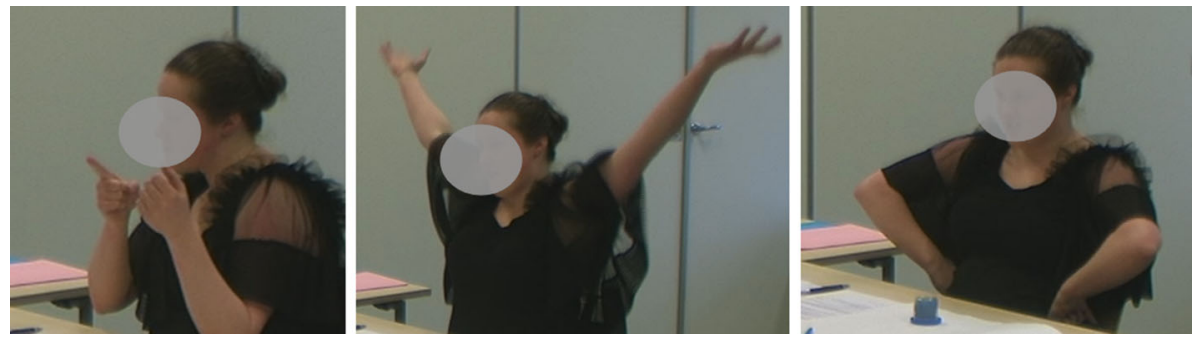

Fig. 6 Example of proposed gestures for triggering scents 
Male: No, but every computer has a webcam and there are several good systems that are able to detect how the user moves. So this already exists.

Female: OK.

Here the female in pair 2 elaborates on the use of gestures to indicate specific scents that should be transmitted and how this could be accommodated in the digital scent system, "doft-box" (scent box) they are designing (see Fig. 6). The other participant claims that such digital solutions are already developed and not novel (=not appropriate for their design proposal). After this sequence, the participants then return to a discussion about the size and technical requirements of their scent box. This is an example of a challenge to common ground that immediately results in a closed transformation, with the participants returning to common ground. Thus, what could have been a starting point for elaborating on new devices and ways of using gestures in the communication of scents, does not lead to an open transformation. Had either the female challenged the claim by the male that bodyrecognition exists and is too trivial to elaborate on, or had the male not made this claim, a possible creative leap could have resulted. Thus we see that the creative process also contains possible paths that could lead to a more elaborate and/or creative solution in the end. In pair two we see many closed transformations of this type, which never get to the stage of challenging common ground in the sense of leading to an open transformation.

Above, we have seen several examples of both open and closed transformations returning the participants to common ground. In the following section we will present examples of open transformations that lead to a new stage in the creative design process.

\section{The transformative closure}

Transformative closure is the process we regard as an expansion of an open transformation involving a shift in focus but including the ideas in the open transformation, i.e. it occurs when the participants are in agreement about what is a viable core design idea. By closure we also mean a strong commitment to the agreement which cannot easily be rejected or reversed without also regressing to an earlier stage of common ground. One basic component of common ground in this design assignment is the instruction presented in the design brief, but it could also comprise generally accepted generic ideas.

Let us now return to where we left off with pair 1 , which is when they had just made a decision to go for a digital solution, and Chequered had proposed a smartphone. Stripes continues to elaborate on this idea:

Chequered: The app linked to... if there is a telephone case or not. It could either be built into the shell or in the case. Like, depending on the moisture level of your hand, that corresponds to your different states of mind. If you are cold and freezing, then this SMS is sent that makes... if it's cold outside it's a scent that makes you warm. I don't know.

Stripes: [laughing]

Chequered: Perhaps two functions, that it is possible to send and to give to yourself. Stripes: Yes.

Chequered: When the hand is cold...

Stripes: It will not be easy to get these compounds in a cellular phone.

Chequered: Yes, that is true.

Stripes: But a slightly more expensive device, linked to a TV? That could work. Like a box with different scents loaded in that.

Chequered [starting to sketch]: It could be a box at home, linked to this. 
At the time of the current study, smartphones are a very important and permeating form of technology, with short text messages (and Ichats) being very popular forms of communication. The idea Chequered presents is a form of semi-automatic chat where part of the function is that the smartphone measures skin temperature and sends some form of scent to the receiver. Stripes does not entirely share the enthusiasm of his design partner even though he shows his understanding of the idea at first by mirroring the hand gesture (Fig. 7). Hesitantly and politely he points out technical limitations to including all the scents in the smartphone, and then incorporates the idea into a conic box to have in the living room, and illustrates this box through his gestures (Fig. 7). Thus, rather than rejecting the idea of a smartphone sensor he introduces a different form of technology which resembles another common and contemporary technology, i.e. a console connected to a TV. Both participants are inspired by this idea. The context of use is now more of a living room device than a personal device. Moreover, the new idea of a larger and more centrally located device solves the technical problem of how to contain all the scents in the device. Both participants approach the idea with enthusiasm.

The device opens up the possibility for several other devices to be connected to it, but it is still this device that administers the scents and which becomes the primary design proposal from the pair. During the sequence, Stripes also does some sketching on paper representations of what the device might look like and how it would work. The device is later discussed more in terms of marketing and consumer segments, and the participants jointly invent the witty name iScenter. All in all, this sequence is an example of how the participants transform one idea into something else and end up in agreement, constructing a new common ground for further development. Instead of actually refuting the first idea of sensor-encasement it is turned into something that could make use of the smartphone but in a different manner. As both participants agree on the device there is a transformative closure in its viability as a design imperative. All in all, the sequence, starting with Chequered proposing a cellular phone, and ending with the name given to the box, iScenter, is over $8 \mathrm{~min}$ long. It is an open transformation that is "saved" from closure through continuously re-establishing common ground, i.e. problems recognized by either of the participants are solved and new ideas incorporated, and it finally results in the strong agreement, the transformative closure. The effort of maintaining common ground this long in an open transformation distinguishes pair 1 from pair 2, as also noted in the former section.

Pair 2 reaches their transformative closure early on, a transformative closure is reached in which the participants are able to settle on a design proposal which they call the "doftbox" (scent box) and which has many characteristics in common with the proposal from pair 1.
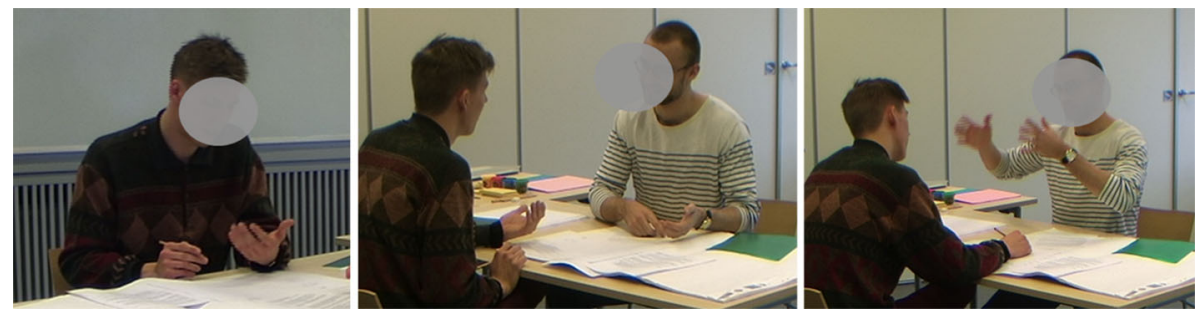

Fig. 7 Example of the development of a transformative closure moving from smartphone to the scent console (iScenter) 


\section{Transition of perspective}

Given a transformative closure in terms of ideas, the participants must continue and transfer the concept into a representation which is more stable and concrete. Sketching in various ways (pen-paper sketching, clay-sketching, Lego, etc.) is a common way to do that (Sun et al. 2014; Suwa and Tversky 1997). As previous research has shown, sketching enables a focus shift in design processes (Sun et al. 2014; Suwa and Tversky 1997). With transition we focus on another aspect of this focus shift, as seen in the two pairs we examined. From being conceptually creative, the focus is now on being practical, concentrating on the form of the artefact, and being constrained in terms of innovation. While transformative closure is a form of creative leap which is agreed upon, sketching is more of a transition in terms of perspective where ideas are adjusted. We will explore this more through two examples.

First, what can be noted is the difference between the pairs as regards reaching a transition from a transformative closure. While pair 1 almost instantly after reaching their transformative closure, also make the transition, pair 2, who reach their transformative closure early on, do not go into the transition until 13 min later into their discussion, that is not long after the sequence described under the section "Expanding and challenging common ground". The transformative closure in pair 2 is facilitated on the one hand by regressing to the instructions, and on the other hand by introducing design materials into the discussion. As they read the instructions out loud accompanied by pointing (see Fig. 8) the participant on the right starts to grab the design materials on the table beside them. She hands over a jar of clay to the other participant and after a while he opens it up and they both laugh. He then quite sentimentally comments on the scent of clay. Both participants start sniffing the scent of the clay-jars (Fig. 8).

After they have smelled the clay, the female participant proposes some gestures that the computer would be able to pick up (as described earlier). The male participant is a little reluctant, stating that computers that can recognize gestures already exist-he is aiming at something more beyond (his idea of) contemporary design. At this point the apparent rejection is rapidly turned into a transformative closure. The female participant quickly reaches over toward the other design materials and begins to tinker with the Lego blocks. The design material causes the participants to focus on scents and the instructions lead them to focus on the design objective - that is digital communication and scent chatting. They discuss how the user should interact with the system. Furthermore, they now start discussing a scent system that is analogous to a surround-system of audio speakers. Using the Lego blocks, they conceptualize how the scent-speakers could be spatially organized.
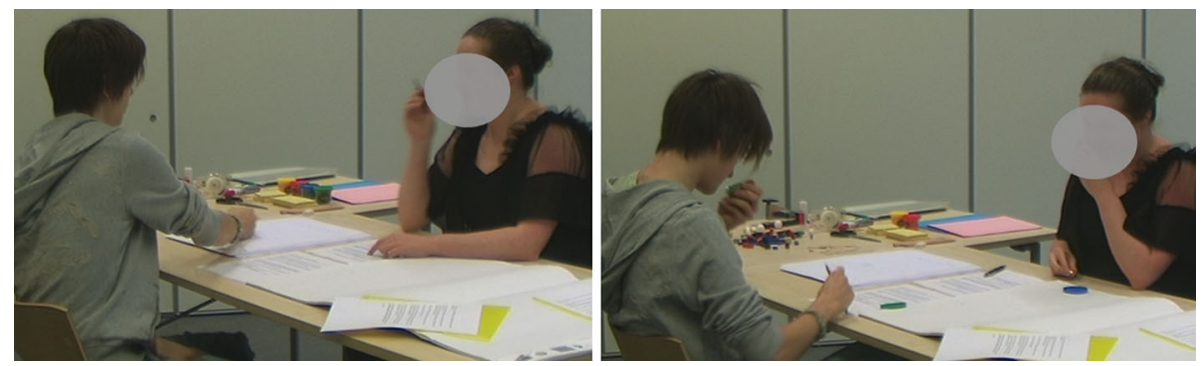

Fig. 8 The clay-jars are used as an inspiring design material, which helps the participants restart the process of idea creation 
With this as a new common ground they discuss how different scent-speakers will send out various scents differing in strength. The material clearly triggers the birth of some new aspects, such as the surround-system, but at the same time enables a transition where their design concept, the scent box, is not challenged any more. The focus is now more on the layout and how the scents are presented to the user. The sketching is done by a fairly simple pen-paper sketch which presents a design showing that the scent box is connected to a computer and that the scent-speakers are organized within a living room (see sketch illustration in Fig. 9). The participants also introduce the game consoles as a way of standardizing the scents that could be presented by the system. Spatially ordered Lego blocks are then attached to the pen-paper sketch. Tinkering with the Lego blocks makes the participants concentrate on how the user receives scents, and they partially abandon the issue of how to interact with the computer by gestures. The sketching activity (but also the fact that time is running out) thus helps them to change perspective and make a transition, from interaction to considering reception and how the system would help the user experience changes in intensity in the scents presented. Later on in their presentation of the concept they return to how the user interacts with the system.

Sketching is used somewhat differently by pair 1 . Here Chequered has made sketches almost from the start of their work. When sketching, it is mainly Chequered who holds the pen, while Stripes is involved in the sketch by pointing and discussing (Fig. 10). At the stage of their transition, which happens just after the sequence described in the last section, they are mainly fine-tuning the concept and describing how different devices are connected (smartphone, game-console, computer). Stripes is also thinking beyond the system's functionalities and discusses aspects of how to organize a project in terms of competences as well as how a user perceives and associates scents. Again, the sketching makes their design work focused and practical rather than associative and creative. At the very end, they return to the design brief and the instructions to check that they have covered all aspects.

\section{Summary of the test sessions}

More generally the test sessions provided data rich in collaborative conceptual design discussions, and thus suitable data for the illustrations of central concepts and applications of the model. In terms of transformative closures, the two teams came up with quite similar solutions to the design task, a box or set of boxes containing scents that can be linked to a
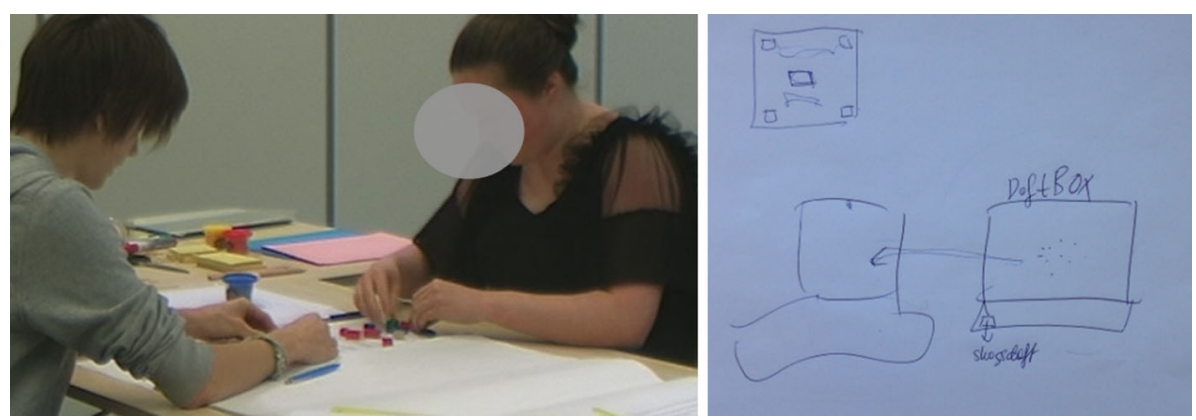

Fig. 9 The participants start to sketch a design proposal by using Lego blocks and pen and paper 

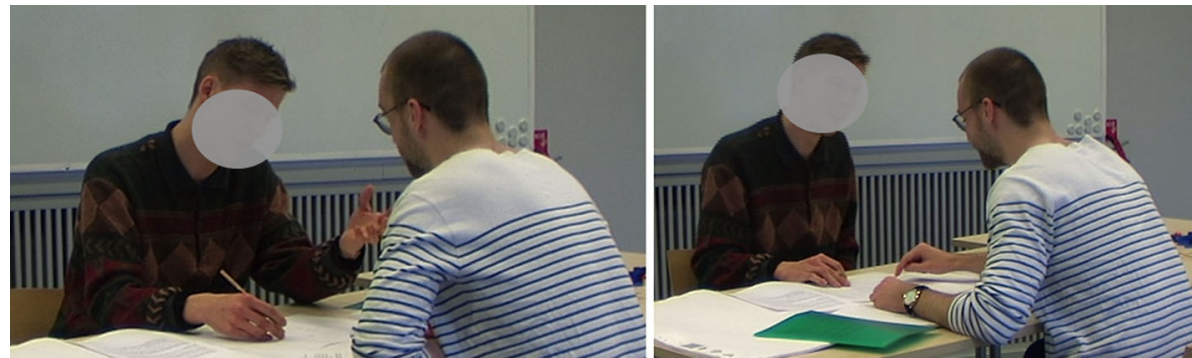

Fig. 10 Sketching as a common activity used by both participants

computer at home. Although other concepts and ideas were discussed by both pairs, our two examples include just one transformative closure each.

But even though the concepts developed by the two pairs were very similar, the ways in which these solutions were reached were quite different. Pair 2 settled on their solution before not even 2 min of the collaborative work had ended and before thoroughly considering other options or ideas. Pair 1 on the other hand was more than half way through their session (more than $15 \mathrm{~min}$ of discussion) when they settled on their solution. Moreover, before reaching their closure, pair 1 had elaborated on several other ideas that had led to closed transformations, i.e. were refuted. Thus we had two pairs with very similar solutions reached through different creative paths. Whereas pair 1 displayed many open transformations, pair 2 ran into many closed transformations. Pair 1 made their transition directly after reaching their transformative closure, while this transition took more than 10 min for pair 2 . In both pairs, tinkering with materials played a key role in the establishment of a transition.

\section{Discussion}

The aim of this study was to develop a model that will enable analysis of cooperative idea generation in conceptual design. We stated four objectives as important for this development.

The first objective was to anchor our model in a model developed by Dorst and Cross (2001) and that used the concepts of problem space and solution space together with the idea of a gradual evolution of these spaces. We believe that we showed how their model could be integrated with our model and understood through the concepts of common ground (returning to the problem space, but with a new understanding each time the individual/pair/group returned) and transformative closure (reaching a solution space that can develop and change during the process). But more empirical studies are needed in order to more clearly relate the two models to each other.

Regarding objective 2, collaborative aspects of conceptual design: We know that designers can lack a common understanding of the task and sometimes disagree on ways to proceed, and that we need to better conceptualize this and include it in our theories of designer thinking and designer processes (c.f. Dorst and Cross 2001; Stempfle and BadkeSchaub 2002). We think, based on both the conceptual elaboration of our model and the analysis of the test sessions, that the phenomenon of grounding and common ground can inform on important aspects of the collaborative creative processes, i.e. how creative work, when collaboratively performed, requires a constant process of grounding, and that 
contributions can be refuted if common ground is not possible to maintain among the participants. Future studies should focus more closely on the processes of maintaining common ground in collaborative design, as this can lead to important insights regarding collaborative design.

Regarding objective 3, the micro aspects of concept formation/ideation: ideas usually do not show up in single utterances, but often gradually evolve through small contributions from the participants, cooperatively elaborating on bits and pieces that gradually transform to more complex concepts (c.f. Wiltschnig et al. 2013, p. 537). These micro aspects seldom become visible in research on collaborative design, as the level of analysis usually focuses on ideas/concepts developed (e.g. Dorst and Cross 2001; Toh and Miller 2015). For example, Dorst and Cross, focusing on the creative event, explain their empirical results and the discussions ("exploration") leading up to this event in the following way:

Our observations confirm that creative design involves a period of exploration in which problem and solution spaces are evolving and are unstable until (temporarily)

fixed by an emergent bridge which identifies a problem-solution pairing. A creative event occurs as the moment of insight at which a problem-solution pair is framed [...]. (p. 435)

Thus, what is of interest to Dorst and Cross is not the "exploration" but the "creative event". We believe that for educational purposes, the mechanisms and workings of the exploration phase are as important as the creative event(s). We believe this exploration is made visible through application of the concepts of "opened transformation" and "closed transformation" in our model.

Regarding the theoretical foundations of the model (objective 4): we believe that our model, based on the theoretical concepts of transformations and common ground, can inform on how the process is held together, and thus complement the model of Dorst and Cross (2001) which has another level of analysis and does not provide theoretical foundations.

However, in order to elaborate more thoroughly on the model and its possible uses, it needs to be further tested and scrutinized. How exactly the model should be used is up to future research to further explore. We see many possible uses. For example to study differences in the processes and character of grounding in design. More experienced designers tend to consider more alternative solutions as compared to novices (Atman et al. 1999, p. 131). The ability to consider alternatives is something that increases with experience, and novices may reject a proposal on bad grounds (c.f. Stempfle and Badke-Schaub 2002, p. 496). Analysing differences in the processes of grounding may lead to new insights into what distinguishes experienced from novice designers. Another possibility would be to use it as a tool in design education, to be used by students and teachers when discussing aspects of collaborative design. It could be used after a group of students have solved a short design task overtly in front of the class, such as in interactionaries, the educational format that the test sessions in this study were based on.

Open Access This article is distributed under the terms of the Creative Commons Attribution 4.0 International License (http://creativecommons.org/licenses/by/4.0/), which permits unrestricted use, distribution, and reproduction in any medium, provided you give appropriate credit to the original author(s) and the source, provide a link to the Creative Commons license, and indicate if changes were made. 


\section{References}

Artman, H., House, D., \& Hultén, M. (2014). Designed by engineers: An analysis of interactionaries with engineering students compared to interaction design students. Designs for Learning, 7(2), 28-56.

Artman, H., Ramberg, R., Sundholm, H., \& Cerratto-Pargman, T. (2005). Action context and target context representations: A case study on collaborative design learning. In Proceedings of the international conference on computer supported collaborative learning (CSCL 2005), Taipei, Taiwan.

Arvola, M., \& Artman, H. (2007). Enactments in interaction design: How designers make sketches behave. Artifact, 1(2), 106-119.

Atman, C. J., Adams, R. S., Cardella, M. E., Turns, J., Mosborg, S., \& Saleem, J. (2007). Engineering design processes: A comparison of students and expert practitioners. Journal of Engineering Education, 96(4), 359-379.

Atman, C. J., Chimka, J. R., Bursic, K. M., \& Nachtmann, H. L. (1999). A comparison of freshman and senior engineering design processes. Design Studies, 20(2), 131-152.

Badran, I. (2007). Enhancing creativity and innovation in engineering education. European Journal of Engineering Education, 32(5), 573-585.

Bijker, W. E. (1995). Of bicycles, bakelites, and bulbs: Toward a theory of sociotechnical change. Cambridge: MIT Press.

Brennan, Susan E. (1998). The grounding problem in conversations with and through computers. In S. R. Fussell \& R. J. Kreuz (Eds.), Social and cognitive psychological approaches to interpersonal communication (pp. 201-225). Hillsdale: Lawrence Erlbaum.

Buxton, B. (2007). Sketching user experience: Getting the design right and the right design. Amsterdam: Elsevier.

Cheung, M. (2012). When mind, heart, and hands meet: Communication design and designers. International Journal of Technology and Design Education, 22(4), 489-511.

Christiaans, H., \& Venselaar, K. (2005). Creativity in design engineering and the role of knowledge: Modelling the expert. International Journal of Technology and Design Education, 15(3), 217-236.

Clark, H. H., \& Brennan, S. A. (1991). Grounding in communication. In L. B. Resnick, J. M. Levine, \& S. D. Teasley (Eds.), Perspectives on socially shared cognition (pp. 127-149). Washington, DC: APA Books.

Clark, H. H., \& Marshall, C. R. (1981). Definite reference and mutual knowledge. In A. K. Joshi, B. Webber, \& I. Sag (Eds.), Elements of discourse understanding (pp. 10-63). Cambridge: Cambridge University Press.

Cropley, D., \& Cropley, A. (2010). Recognizing and fostering creativity in technological design education. International Journal of Technology and Design Education, 20(3), 345-358.

Cross, N. (1997). Descriptive models of creative design: Application to an example. Design Studies, 18(4), 427-455.

Dorst, K. (2006). Design problems and design paradoxes. Design Issues, 22(3), 4-17.

Dorst, K. (2011). The core of 'design thinking' and its application. Design Studies, 32(6), 521-532.

Dorst, K., \& Cross, N. (2001). Creativity in the design process: Co-evolution of problem-solution. Design Studies, 22(5), 425-437.

Engeström,Y. (1987). Learning by expanding: An activity-Theoretical approach to developmental research. Dissertation: University of Helsinki.

Esjeholm, B.-T. (2015). Design knowledge interplayed with student creativity in D\&T projects. International Journal of Technology and Design Education, 25(2), 227-243.

Hendry, G. D., \& Tomitsch, M. (2014). Implementing an exemplar-based approach in an interaction design subject: Enhancing students' awareness of the need to be creative. International Journal of Technology and Design Education, 24(3), 337-348.

Howard, T. J., Culley, S. J., \& Dekoninck, E. (2008). Describing the creative design process by the integration of engineering design and cognitive psychology literature. Design Studies, 29(2), 160-180.

Hutchins, E. (1995). Cognition in the wild. Cambridge: MIT Press.

Jewitt, C. (2008). Multimodality and literacy in school classrooms. Review of Research in Education, 32(1), 241-267.

Jordan, B., \& Henderson, A. (1995). Interaction analysis: Foundations and practice. The Journal of the Learning Sciences, 4(1), 39-103.

Juhl, J., \& Lindegaard, H. (2013). Representations and visual synthesis in engineering design. Journal of Engineering Education, 102(1), 20-50.

Klein, H. K., \& Kleinman, D. L. (2002). The social construction of technology: Structural considerations. Science, Technology and Human Values, 27(1), 28-52. 
Lindström, L. (2006). Creativity: What is it? Can you assess it? Can it be taught? The International Journal of Art \& Design Education, 25(1), 53-66.

Maher, M. L., Poon, J., \& Boulanger, S. (1996). Formalising design exploration as co-evolution: A combined gene approach. In J. S. Gero \& F. Sudweeks (Eds.), Advances in formal design methods for CAD (pp. 3-30). London: Chapman \& Hall.

Pickering, M. J., \& Garrod, S. (2004). Toward a mechanistic psychology of dialogue. Behavioral and Brain Sciences, 27(2), 169-190.

Plucker, J. A., Beghetto, R. A., \& Dow, G. T. (2004). Why isn't creativity more important to educational psychologists? Potential, pitfalls, and future directions in creativity research. Educational Psychologist, 39(2), 83-97.

Ramberg, R., Artman, H., \& Karlgren, K. (2013). Designing learning opportunities in interaction design: Interactionaries as a means to study and teach student design processes. Designs for Learning, 6(1-2), 30-49.

Rivard, K., \& Faste, H (2012). How learning works in design education: Educating for creative awareness through formative reflexivity. In Proceedings of the designing interactive systems conference (DIS) (Vol. 12, pp 298-307).

Rutland, M., \& Barlex, D. (2008). Perspectives on pupil creativity in design and technology in the lower secondary curriculum in England. International Journal of Technology and Design Education, 18(2), $139-165$.

Salomon, G. (Ed.). (1993). Distributed cognitions: Psychological and educational considerations. Cambridge: Cambridge University Press.

Selander, S. (2008). Designs for learning: A theoretical perspective. Designs for Learning, 1(1), 10-22.

Selander, S., \& Kress, G. (2010). Design för lärande: Ett multimodalt perspektiv. Stockholm: Norstedts förlag.

Siu, K. W. M., \& Wong, Y. L. (2016). Fostering creativity from an emotional perspective: Do teachers recognise and handle students' emotions? International Journal of Technology and Design Education, 26(1), 105-121.

Stempfle, J., \& Badke-Schaub, P. (2002). Thinking in design teams-An analysis of team communication. Design Studies, 23(5), 473-496.

Sun, L., Xiang, W., Chai, C., Wang, C., \& Huang, Q. (2014). Creative segment: A descriptive theory applied to computer-aided sketching. Design Studies, 35(1), 54-79.

Sundholm, H., Artman, H., \& Ramberg, R. (2004). Backdoor creativity: Technological support and collaborative creativity. In Proceedings of the conference on the design of cooperative systems (COOP '04), Heyeres, France.

Suwa, M., \& Tversky, B. (1997). What do architects and students perceive in their design sketches? A protocol analysis. Design Studies, 18(4), 385-403.

Tholander, J., Karlgren, K., Ramberg, R., \& Sökjer, P. (2008). Where all the interaction is: Sketching in interaction design as an embodied practice. In Proceedings of the 7th ACM conference on designing interactive systems (DIS 2008), Cape Town, South Africa.

Toh, C. A., \& Miller, S. R. (2015). How engineering teams select design concepts: A view through the lens of creativity? Design Studies, 38, 111-138.

Vygotsky, L. (1986). Thought and language. Cambridge: MIT Press.

Wiltschnig, S., Christensen, B., \& Ball, L. J. (2013). Collaborative problem-Solution co-evolution in creative design. Design Studies, 34(5), 515-542.

Wong, Y. L., \& Siu, K. W. M. (2012). A model of creative design process for fostering creativity of students in design education. International Journal of Technology and Design Education, 22(4), 437-450.

Zhou, C. (2012). Fostering creative engineers: A key to face the complexity of engineering practice. European Journal of Engineering Education, 37(4), 343-353. 